\title{
Prólogo convivial para Roberto Fernández Retamar
}

\author{
Adriana Crolla \\ Centro Estudios Comparados - \\ Universidad Nacional del Litoral
}

En momentos en que cerrábamos la edición del presente número tomamos conocimiento de la infausta noticia del fallecimiento de Roberto Fernández Retamar.

El entrañable ensayista y comparatista cubano integra nuestro Comité Honorario desde hace más de una década. Recuerdo vivamente el interesante diálogo que compartí durante el XVIII Congreso de la Asociación Internacional de Literatura Comparada, organizado por Eduardo Coutinho en Río de Janeiro entre el 30 de julio y el 4 de agosto de 2007; y el entusiasmo con que aceptó acompańarnos, toda vez que constituía una publicación de un país al que lo unían profundos afectos y porque, ya desde el nombre, podía, como nos manifestó, tejer un hilo invisible con su celebrado Borges.

Tuvimos el privilegio de que nos permitiera publicar en el volumen 7 (2007) el texto titulado Varias maneras de mirar a un irlo. Digo, a una literatura. ${ }^{1}$ Poco tiempo después, con extrema generosidad me hizo llegar por correo las copias de dos ensayos que resultaba difícil conseguir, y que escribiera en dos momentos diferentes de su vida en un afán de archivar en palabras la memoria de sus lecturas borgeanas.

A fines de febrero de este año reestablecí el contacto para solicitarle nos enviara un $\mathrm{CV}$ actualizado, pues debíamos cumplir con ciertas pautas de los procesos de indexación. En el intercambio de mensajes surgió la invitación para contar con una nueva colaboración y sin dilaciones envió «Prólogo a Prólogos para la Memoria», texto que, como nos explicó, acababa de escribir para prologar un libro que las autoridades de Casa de las Américas estaban diseñando para celebrar los sesenta años de intensa labor literaria desplegada por esa institución.

La lectura del mismo nos provee con pormenorizado detalle en tonos de archivo, una enorme cantidad de nombres de autores y prologuistas acogidos en sucesivas ediciones a lo largo de estas seis décadas. Es también en un homenaje a las letras latinoamericanas y caribeñas en su más variado y abigarrado conjunto.

El prólogo de Fernández Retamar constituye el homenaje de un Calibán de las Letras a la literatura y a la fruición que la misma depara. Para nosotros, en especial, representa mucho en términos afectivos, pues nos permite atesorar y ofrecer a nuestros lectores su quizás último gran esfuerzo para cartografiar canibalescamente

\footnotetext{
- Cavaliere de la República Italiana por la Orden Stella d'Italia, Directora del Centro de Estudios Comparados y de su revista El Hilo de la Fábula, del Portal de la Memoria Gringa y del Programa de Estudios sobre Migraciones Lina y Charles Beck-Bernard. (http://www.fhuc.unl.edu.ar/portalgringo/crear/gringa/index_e.html). Profesora e investigadora en la Facultad de Humanidades y Ciencias de la Universidad Nacional del Litoral
} 
toda una vida dedicada a mirar el mundo desde la lectura, y desde una perspectiva marcadamente comparada.

«Prólogo a Prólogos para la Memoria» había sido pensado para la primera sección de nuestra revista. Pero las actuales circunstancias justifican que generemos una sección para el Convivio. Y junto al texto de Fernández Retamar, en sentido homenaje, me permito incluir un breve texto, escrito en primera versión a la luz de aquellos ensayos, y ahora reescrito para compartirlo.

\section{El otro Borges de Roberto Fernández Retamar}

Hace unos años, el célebre escritor cubano Fernández Retamar, con gran generosidad, me hizo llegar dos ensayos que escribiera en honor a Borges. Uno del ańo 1986 titulado Encuentro con Jorge Luis Borges ${ }^{2}$ y el segundo de 1999: Cómo yo amé a mi Borges ${ }^{3}$, con el que elaboré un trabajo que llevé a un seminario sobre Borges comparatista a la Universitè de Lyon, Francia, en $2013^{4}$.

Fernández Retamar escribió el primero para prologar una compilación de Páginas escogidas de J.L. Borges, para Casa de las Américas. Libro para el que pidió la anuencia al mismísimo Borges, a quien tuviera la oportunidad de visitar en Buenos Aires un 16 de septiembre de 1985 .

El relato de los detalles de esa memorable circunstancia denota la emoción que embargó al visitante y la intensidad de la experiencia. La que a despecho de los años, y sin haber sido grabada ni recuperada en notas, es recordada en sus mínimos detalles. El diálogo, pormenorizadamente rememorado, denota la necesidad de $\mathrm{F}$. Retamar de restañar una falta. Y así lo cita:

-Debo añadirle que he escrito algunas cosas duras sobre usted, Borges, pero probablemente no más duras que las que usted escribió sobre Darío o Lugones. Y sin embargo....

Borges dice, como para sí: —Fueron mis maestros. (1986: 6)

Recuerdo apenado del cubano por las opiniones que deslizara en su Calibán de 1971 donde recupera al personaje shakespeariano como metáfora de la «América mestiza» que preconizaba José Martí. En dicho texto reprochaba a Borges haber dedicado su traducción de Hojas de hierba de Walt Whitman al presidente de los EEUU, Richard Nixon, y criticaba su manifiesto rechazo a la Revolución Cubana. Muchos años después, en el ensayo de 1999, llegó a reconocer:

Pero Borges siguió disparando sus declaraciones y firmando manifiestos. Y en días alterados de 1971, cuando escribí el ensayo Caliban (que entonces se llamaba Calibán), le dediqué allí declaraciones ácidas, aunque diciendo que era un escritor realmente importante, cuyas páginas no era posible leer sin admiración. Doy por conocidas esas observaciones, pues el ensayo lo es. Y, pasada la alteración, en trabajos sucesivos sobre el tema fui matizando mis juicios, y entre otras cosas le reconocí a la obra borgeana el carácter calibanesco que me reclamaron con razón algunos críticos... En Adiós a Calibán de 1993, conté incluso la satisfacción que me produjo un joven escritor al decirme, recién aparecido aquel ensayo de 1971, que lo había leído, y que no sabía que yo admirara tanto a Borges. (1999: 7) 
Si las modulaciones ideológicas son naturales en toda línea vital, muchos argentinos también aprendimos tarde, como el fervoroso lector cubano, a distinguir la distancia entre la postura política y el esteticismo verbal, que nunca apartó a Borges de un profundo compromiso con «nuestro mundo cuya rareza se complace en señalar».

En ese encuentro fervoroso de 1985, Fernández Retamar pudo manifestarle su admiración y también regodearse de haberse iniciado en su lectura desde los márgenes de un barrio orillero de La Habana llamado La Víbora, a sus 15 años, más o menos en 1945. Por aquellos años se editaba en ese barrio una revista juvenil Alba, y a él le encargaban la sección «Libros». Allí escribió sus primeras líneas sobre el Borges traductor de La Metamorfosis y compilador, junto a Bioy de la primera serie «de los mejores cuentos policiales» (F. Retamar, 1999: 2). Al mismo tiempo recuerda cómo gustaba frecuentar las colaboraciones borgeanas en Sur, y detenerse sobre todo en los espacios marginales o al final de la revista, donde Borges, con letra minúscula, se presentaba "como una suerte de escritor irregular o marginal (traductor, prologuista, antólogo, editor, comentarista)... [y así] entró Borges a mi vida» (1999: 2).

Luego se le irá imponiendo el Borges poeta, descubierto en los libros primeros, comprados en librerías laterales de La Habana, en una época en que ni el argentino ni la literatura hispánica habían alcanzado todavía la internacionalización posterior. «Estaba fascinado por Borges», reconoce Fernández Retamar y esa fascinación lo impulsa a hablar de su obra, a veces hasta en notas anónimas, pero siempre trascendentes, como aquélla escrita después de la Revolución Cubana para responderle imaginándose ser un ghibelino enfrentado a su Alighieri (que eso era Borges para él). Asumir esa figura es, conjeturo, sentirse Farinata degli Uberti. Un moderno ghibelino que más allá de las controversias, reconoce la ética del contrario, y lo enaltece como hace Dante retratando soberbio a Farinata, aun colocándolo en el círculo infernal de los heréticos.

Muerto Borges, el crítico cubano se verá imposibilitado de cumplir la promesa de entregar en manos del argentino la publicación prometida de Casa de las Américas. Pero no deja de incluir en el número 158, una página sin firma, en su homenaje, donde condensa admirablemente su pasión por el argentino:

Nos habíamos acostumbrado a la sorpresa de tenerlo entre nosotros, como uno se acostumbra, hasta parecer invisible, a la maravilla de los amaneceres o de las noches estrelladas... Quizás, hubiera preferido ser un compadrito. Pero fue Borges, e hizo variar el rumbo a más de una literatura. Se le perdonarán sus errores. Se le recordará mientras existan la lengua castellana y el asombro de vivir. (1999: 8)

Y lo celebra plagiando la misma frase que Borges expresara al entrarse de la muerte de Unamuno: El primer escritor de nuestro idioma acaba de morir. Ya al final del ensayo, Fernández Retamar incorpora un poema propio en su honor, el que dice escribe, pidiendo la voz a su maestro. Y lo afirma con palabras que certifican la presencia semafórica y paradigmática que Borges ejerció sobre él desde que comenzara a inventar sus propias figuraciones:

Estoy seguro de que no escribiría como lo hago de no haberlo leído durante más de medio siglo con pasión, con gratitud y placer, aunque, según ya adelanté, él sea inocente de ese impacto en los demás. Como Borges dijo de Becher, de Whitman, de Cansino Assens, de Macedonio, de Carlyle, de Swinborne, hubo un tiempo en que él no fue para mí un escritor más, sino la literatura. (1999: 9) 
Michos años después retoma anécdotas, alabanzas y justificaciones, y cierra el ciclo de esta manera:

Una de las cosas gratas que me ocurrieron cuando apareció Calibán fue que un joven escritor que era entonces alumno mío me dijo que lo había leído, y que no sabía que yo admirara tanto a Borges. Me encantó saber que a despecho de la irritación, afortunadamente pasajera, por debajo latía entero el amor, más permanente. Que él se manifieste con el viento a favor, está bien. Mejor está que lo haga con el viento en contra. Pues aquélla era, por mi parte, una pelea de familia. Y en cuanto a Borges, supongo que ni se enteró de sus términos. Como tuve ocasión de decirle a él mismo en 1985 (entiendo que con su acuerdo), que yo no había sido más duro con él que él con Darío y Lugones. Y aún ahora no sé cuál de los dos, él o yo tenía más o menos razón, más o menos pasión al proceder como procedimos (2004: 75)5

Cierro este diálogo convivial con Fernández Retamar con una propuesta de lectura para que el hilo de la fábula siga generando nuevos e inesperados diseńos ${ }^{6}$.

Desde la mirada de un outsider que supo amar mucho a la Argentina aún sin privarse de seńalar sus contradicciones. Lo que nos permite adentrarnos en la trama de sus lecturas, las que nos reconfiguran a partir de un vasto, ecléctico e inteligente espejo.

${ }^{1}$ El texto puede ser consultado también en el volumen que aglutina las presentaciones destacadas del congreso. Editado por Eduardo Coutinho bajo el título: Beyond Binarisms. Identities in Process: Studies in Comparative Literature, Río de Janeiro: Aeroplano, 2009.

${ }^{2}$ Prólogo de las Páginas escogidas de Jorge Luis Borges, compilación a cargo de Fernández Retamar para Casa de las Américas, La Habana, 1988.

${ }^{3}$ Leído en el encuentro de escritores Borges y yo. Diálogo con las letras Latinoamericanas, realizado en el Fondo Nacional de las Artes, Buenos Aires, entre el 2 y el 4 de junio de 1999.

${ }^{4}$ Crolla, Adriana. Jorge Luis Borges: leer y escribir al otro en la constitución de los paradigmas de ficcionalización literaria (mimeo)

5 Fernández Retamar, R: «Calibán» en Casa de las Américas, n 68, septiembre, octubre, 1971. La versión que utilizamos es la revisada y actualizada por el mismo autor, publicada bajo el título Todo Caliban, Buenos Aires: CLACSO, 2004

${ }^{6}$ Fernández Retamar, R. (1993) Fervor de la Argentina. Antología personal. Buenos Aires: Ediciones del Sol.
}

\section{Crolla, Adriana}

«Prólogo convivial para Roberto Fernández Retamar». El hilo de la fábula. Revista anual del Centro de Estudios Comparados (19), 221-224. 